\title{
Cabin Air Quality Dynamics On Board the International Space Station
}

\author{
J. L. Perry \\ National Aeronautics and Space Administration \\ B. V. Peterson \\ Dynamac Corporation
}

Copyright $\odot 2003$ SAE International

\begin{abstract}
Spacecraft cabin air quality is influenced by a variety of factors. Beyond normal equipment offgassing and crew metabolic loads, the vehicle's operational configuration contributes significantly to overall air quality. Leaks from system equipment and payload facilities, operational status of the atmospheric scrubbing systems, and the introduction of new equipment and modules to the vehicle all influence air quality. The dynamics associated with changes in the International Space Station's (ISS) configuration since the launch of the U.S. Segment's laboratory module, Destiny, is summarized. Key classes of trace chemical contaminants that are important to crew health and equipment performance are emphasized. The temporary effects associated with attaching each multi-purpose logistics module (MPLM) to the ISS and influence of in-flight air quality on the post-flight ground processing of the MPLM are explored.
\end{abstract}

\section{INTRODUCTION}

\section{DESIGN CONSIDERATIONS}

A crewed spacecraft cabin is considered the "ultimate in tight building design".[1] As with a tight building, low leakage rates, a small specific volume, and the use of a host of advanced materials of construction contribute to conditions that may lead to unhealthy air quality if appropriate care is not exercised during the design, construction, and operation of a spacecraft. For this reason, designing for cabin air quality must balance a large number of competing design elements to achieve acceptable cabin air quality. These include spacecraft cabin characteristics, crew size, mission duration and objectives, materials selection, manufacturing, and vehicle maintainability that, as a whole, constitute a set of passive contamination controls. The entire design process occurs within the boundary set by the air quality standards.[2] It is a complex, challenging process but not impossible.

\section{CONTAMINATION SOURCES}

While the passive controls implemented during the vehicle design and manufacturing processes serve to limit the magnitude of contamination sources, active controls must be provided on board and flight operations specialists must consider how the vehicle's configuration, life support system operational status, and a host of crew activities may affect air quality. Some operational parameters may be easily controlled from the ground. Other parameters depend upon crewmembers' awareness of their actions and the resulting effect on their own health as well as the vehicle's health.

While attention during the design and manufacture of the spacecraft passively minimizes trace chemical contaminant offgassing rates, they cannot be eliminated. Equipment offgassing along with human metabolic products from the crew are primary contamination sources. As long as equipment and a crew are present, contaminants will be generated. Other major contamination sources include equipment leaks, various crew activities, and payload operations as well as cargo and crew transfer vehicle docking operations. The dynamics associated with the activation of new modules has been shown to be significant. Reference 2 provides a more detailed discussion of the interaction between contamination sources and control means.

Because contamination sources cannot be fully eliminated by passive means, active air quality control systems are deployed on board. The International Space Station (ISS) employs processes based upon a combination of adsorption by activated carbon, thermal catalytic oxidation, ambient temperature catalytic oxidation, and chemical adsorption to remove trace chemical contaminants from the cabin atmosphere. Two primary control units, the trace contaminant control subassembly (TCCS) located in the U.S. Segment's laboratory module, Destiny, and the micro-contaminant filtering system, known by its Russian acronym BMP and located in the service module, Zvezda, actively remove trace contami- 
nants from the cabin atmosphere. References 3 through 5 provide details on the basic TCCS and BMP process designs.

\section{TRACE CHEMICAL CONTAMINATION CONTROL ON BOARD ISS}

The atmosphere revitalization equipment on board the ISS has been providing the crew with a habitable working environment for more than 2 years. Beginning in November 2000, the ISS has been continually occupied. Between November 2000 and February 2001, the trace contaminant and carbon dioxide control systems housed in the Russian Segment's service module, Zvezda, processed the cabin air. In February 2001, the U.S. laboratory module, Destiny, was activated. Destiny's activation added redundant trace contaminant and carbon dioxide control equipment. During normal operations both trace contaminant control units are operating while only one of the carbon dioxide control units operates. The carbon dioxide control unit in Zvezda, known as the Vozdukh, is the primary carbon dioxide control system while the carbon dioxide removal assembly (CDRA) located in the Destiny provides redundant capability. Details on the environmental control and life support equipment on board the ISS may be found in Reference 6 .

During the more than 2 years of crewed operations, cabin air quality samples have been collected at approximately 1-month intervals. These samples are collected using evacuated grab sample containers and are returned to NASA laboratories on the ground for analysis. Periodically, additional samples are collected if the crew or ground personnel suspect an air quality anomaly. In addition, both NASA and Russian environmental health investigators use sampling methods that trap trace chemical contaminants onto adsorbent media. These samples are also returned to laboratories on the ground for analysis. Reference 7 summarizes the primary sampling and analytical methods employed by NASA and Russian air quality specialists.

A variety of chemical functional classes have been reported from air quality sample chemical analysis. Alcohols, aldehydes, ethers, esters, ketones, aromatics, halocarbons, aliphatic and olefinic non-methane hydrocarbons, organosilicone compounds, methane, and carbon monoxide are typically reported. Figure 1 shows the average composition of the total trace contaminant load by functional class. This average composition is representative of the station's configuration as of June 2002. As Figure 1 shows, methane, organosilicone compounds, alcohols, hydrogen, and carbon monoxide tend to dominate the trace contaminant load.

Variations in the trace contaminant load with time and location can and do occur. The cabin concentration of specific functional classes and individual contaminants may undergo temporal changes, spatial changes, or both. Routine engineering evaluation of cabin air quality data demonstrates the interplay between the various op- erational factors that influence cabin air quality. The following discussion addresses specific cases of temporal and spatial variation of cabin concentrations for methane, polar volatile organic compounds (VOCs), nonmethane VOCs, and selected halocarbons. These cases illustrate how the vehicle configuration and onboard equipment operation affect trace contaminant loading. The air quality dynamics associated with cargo vehicle docking operations is also explored.

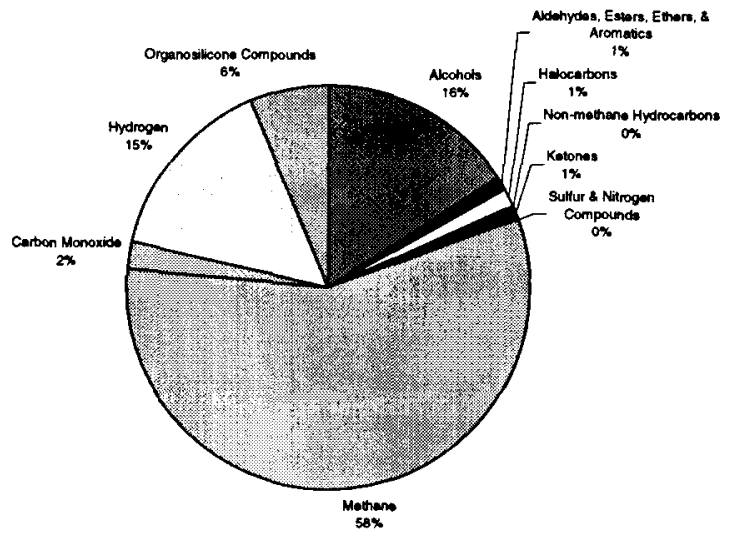

Figure 1. Average Cabin Trace Contaminant Load Composition On Board ISS

\section{TEMPORAL DYNAMICS}

Air quality changes over time are influenced significantly by the station's configuration and the operational status of the on-board active contamination control systems. As well, equipment failures that result in releases of volatile contaminants into the cabin also contribute to these variations. Cabin concentrations for methane, halocarbons, and volatile polar organic compounds are examined by the following discussion to illustrate air quality temporal dynamics.

\section{Methane}

Methane control on board the ISS reflects three fairly distinct operational phases as seen by Figure 2. The first covers early crew entry (ingress) operations. During this phase, no permanent crew resided on the station. Crews visited periodically for assembly missions and then left. As can be seen in Figure 2, the initial methane concentration was low and then rose to approximately 30 $\mathrm{mg} / \mathrm{m}^{3}$ as the shuttle's and ISS's atmospheres mixed. Also, the station had no active means for removing methane from the cabin air, therefore, a persistent concentration was characteristic of this period. Once the Zvezda service module was activated and the first permanent crew arrived, the methane concentrations increased dramatically. Concentrations peaked at approximately $210 \mathrm{mg} / \mathrm{m}^{3}$. Even then, they were much lower than the $3,800 \mathrm{mg} / \mathrm{m}^{3}$ spacecraft maximum allowable concentration (SMAC).[8] During this period, there was no active methane removal capability on board. The control mechanism was primarily overboard leakage and 
dilution from fresh air provided by logistics vehicles and the shuttle as they arrived. When Destiny was activated, the methane concentration immediately declined to less than $10 \mathrm{mg} / \mathrm{m}^{3}$. This corresponded to the TCCS's activation. The concentration has been maintained to less than $20 \mathrm{mg} / \mathrm{m}^{3}$ since with the exception of two periods when the TCCS was not operating. In both instances, the methane concentration returned to a low level as soon as the TCCS restarted.

\section{Halocarbons}

Halocarbons of interest include dichloromethane, bromotrifluoromethane (Halon 1301), and octafluoropropane (Freon 218). Dichloromethane is a key compound used to size the TCCS's activated carbon bed. It is used in manufacturing for cleaning and degreasing and is a common component of equipment offgassing. Flight systems use halocarbons for various purposes. Halon 1301 is the fire extinguishant used on board the shuttle and Freon 218 is a working fluid in Zvezda's air conditioning system. Examination of cabin air quality as it relates to these compounds illustrates the resulting effects of vehicle docking and on board system failures.

As Figure 3 shows, dichloromethane has been maintained well below its SMAC of $10 \mathrm{mg} / \mathrm{m}^{3}$.[9] The highest concentrations have been recorded in the multi-purpose logistics modules (MPLM) when the hatch is first opened. These high concentrations in the MPLM ultimately are diluted throughout the entire ISS cabin. Corresponding to MPLM first entry operations, concentration spikes in the ISS cabin demonstrate how a newly docked cargo vehicle can affect cabin air quality.

Figure 4 shows the Halon 1301 concentration during all ISS operational phases through June 2002. During the station's early assembly stages, concentrations up to approximately $3 \mathrm{mg} / \mathrm{m}^{3}$ were reported. As the ISS does not have Halon-based fire extinguishers on board, the source is from the shuttle. A limited active contamination control active control capability was on board the ISS during the early assembly stages. Therefore the concentration increased until the TCCS was activated in February 2001. The Halon 1301 concentration has been maintained at very low levels since and also reflects the period when the TCCS was shut off where the concentration rose slightly.

After Zvezda was activated, Freon 218 began to be found in the cabin air quality samples. Freon 218 is a coolant fluid used in Zvezda's air conditioning system. Over time, the concentration increased, slowly at first and then rapidly. Peak concentrations reached more than $600 \mathrm{mg} / \mathrm{m}^{3}$. Figure 5 shows this trend indicating a leak from the air conditioning system. Ultimately over a period of months, the leaks were repaired and concentrations reduced to less than $20 \mathrm{mg} / \mathrm{m}^{3}$. This situation demonstrates the effects that system leaks may have. While Freon 218 did not exceed its SMAC of 85,000 $\mathrm{mg} / \mathrm{m}^{3}$, it is difficult to remove from the cabin atmosphere and active contamination control resources must be managed efficiently to recover from the leak.[10] The Freon 218 concentration decay rate indicates less than $1 \%$ single pass removal efficiency by the BMP alone. Beyond removal by the BMP, volumetric dilution was provided periodically when logistics and crew transfer vehicles docked. The beneficial effects of these volumetric dilutions, however, were quite small.

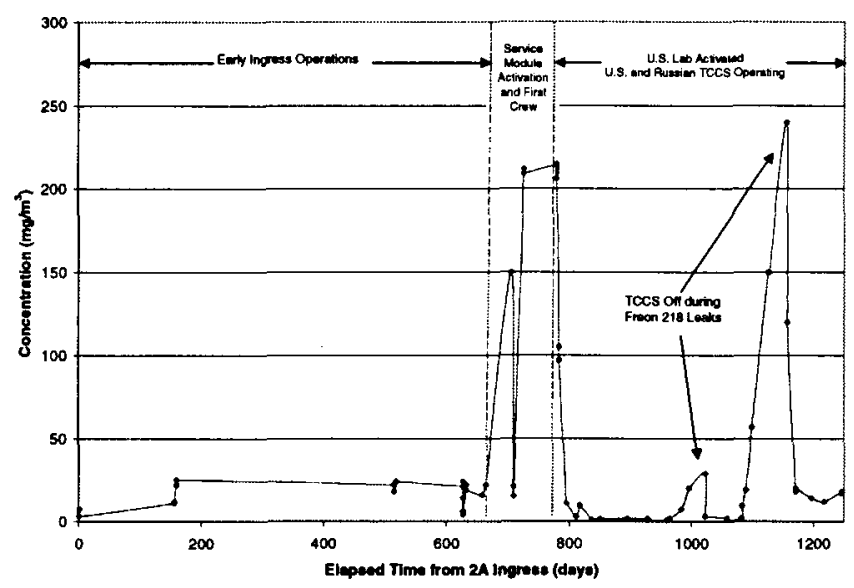

Figure 2. Methane concentration on board the ISS.

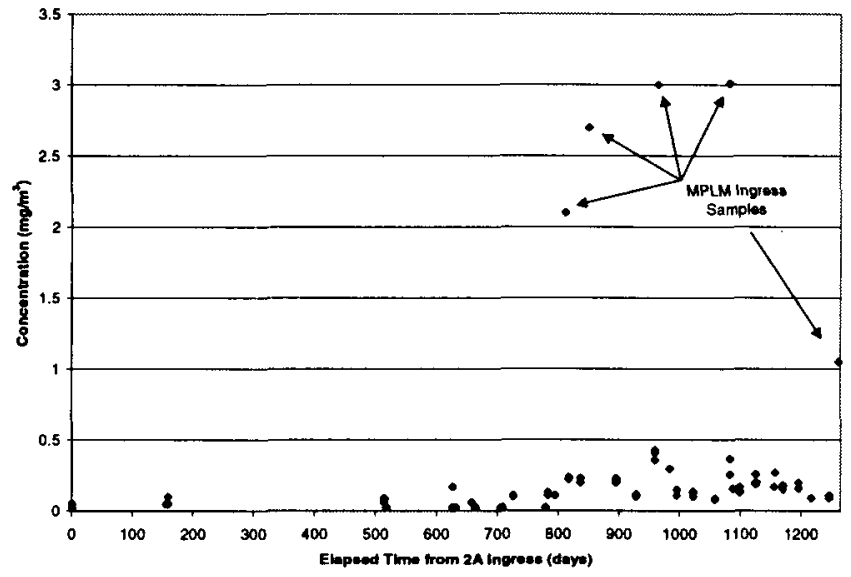

Figure 3. Dichloromethane concentration in the ISS cabin

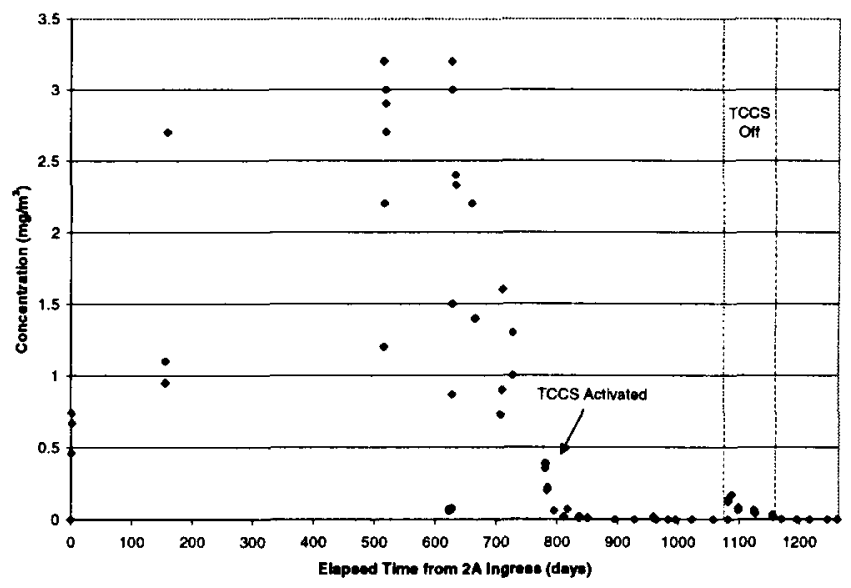

Figure 4. Halon 1301 concentration in the ISS cabin 


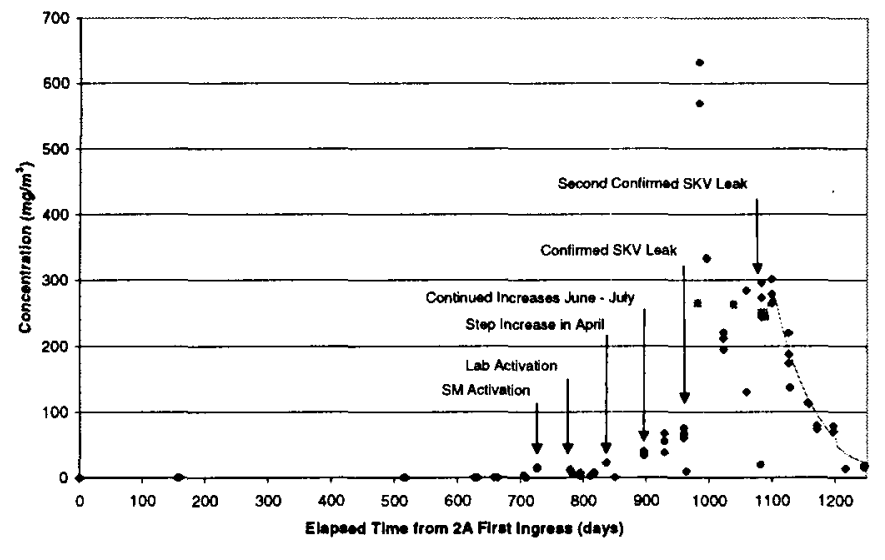

Figure 5. Freon 218 concentration in the ISS cabin

Polar and Non-methane Volatile Organic Compounds

The total polar VOC loading in the ISS cabin is a concern. They can affect the process economics of the onboard water reclamation and processing systems. Polar VOCs of most concern include methanol, ethanol, nbutanol, 2-propanol, and 2-propanone.[11] Figure 6 shows the polar VOC loading in the ISS cabin from the station's early assembly stages in December 1998 through May 2002. Dynamic effects during the early assembly phase are characterized by concentration decay between the beginning and end of each period that the shuttle orbiter docked to the station. This is attributed to volumetric dilution of the ISS cabin with air containing lesser contamination from the shuttle orbiter cabin. The volumetric dilution effects during these early missions were much more pronounced because the ISS and shuttle orbiter cabin volumes were nearly equal.

Figure 6 also illustrates dynamics associated with various vehicle configuration and operational scenarios. Four cases are of interest. The first is STS-101/2A.2a when a maximum 2-propanol concentration of $13 \mathrm{mg} / \mathrm{m}^{3}$ was noted at the end of the docked phase. During the same time, the 2-propanol concentration in the shuttle orbiter was $10 \mathrm{mg} / \mathrm{m}^{3}$. This increase was indicative of inflight 2-propanol use by the crew. The second case involves ethanol concentrations as high as $25 \mathrm{mg} / \mathrm{m}^{3}$ during entry of unventilated volumes in the PMA-1, Zvezda, and the Progress during STS-106/2A.2b. After activating the ventilation and contamination control systems, the concentration throughout the ISS was reduced to 2.7 $\mathrm{mg} / \mathrm{m}^{3}$. The third case occurred just before STS-105 was launched when $70 \mathrm{mg} / \mathrm{m}^{3}$ methanol was found in a sample collected in the functional cargo block, Zarya. Samples collected later showed the methanol concentration had been reduced to nearly $2 \mathrm{mg} / \mathrm{m}^{3}$. As can be the case with air quality issues on occasion, the methanol's source could not be determined. The final case involves the regeneration of a metal oxide canister used to remove carbon dioxide from the space suite during extravehicular activities. In February 2001, the crew initiated a regeneration operation in the station's airlock. The canister being regenerated had been exposed to the station's atmosphere for approximately 6 months and had adsorbed some contaminants. Shortly after beginning the regeneration, the crew reported a strong odor. The crew stopped the metal oxide canister regeneration process and collected grab samples. Analysis of the samples showed a high concentration of $\mathrm{n}$-butanol and several aromatic compounds that accounted for the odor. The crew isolated the U.S. Segment modules affected by the odor and retreated to the Russian Segment. The TCCS was activated and a sample collected the next day showed the air quality was again acceptable.

Figure 7 shows the non-methane VOC concentration over the same time period excluding the overwhelming contribution from Freon 218. Without considering Freon 218 , the non-methane VOC concentration has typically ranged between approximately $5 \mathrm{mg} / \mathrm{m}^{3}$ and $15 \mathrm{mg} / \mathrm{m}^{3}$. Comparison to Figure 6 for the polar VOCs shows some striking similarities. In particular the high concentrations during the $2 \mathrm{~A} .2 \mathrm{~b}$ crew entry operation, the methanol event in Zarya, and the METOX regeneration odor event are notable. This indicates that polar VOCs are a major contributor to the total non-methane VOC load in the cabin. Figure 8 shows the non-methane VOC concentration excluding both Freon 218 and the polar VOCs. Comparison of Figures 7 and 8 show that polar VOCs typically account for as much as half of the non-methane VOC load. Therefore, particular attention must be given to the use of polar VOCs during vehicle ground processing and flight operations.

The dynamics associated with the polar VOCs and nonmethane VOCs illustrate that even when precautions are taken, the activation of new modules and the addition of new equipment to the ISS will cause dynamic changes in cabin air quality. These changes may be short-lived but they also can have effects on the crew and require changes to the vehicle's configuration. Therefore, the design, manufacturing, and operations processes must employ a robust, conservative contamination control program to ensure that proper cabin air quality is maintained.

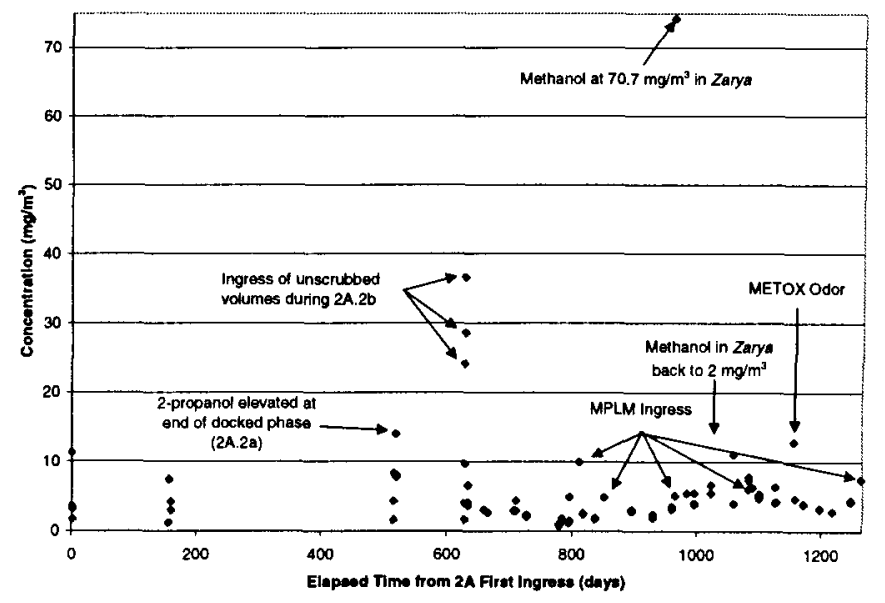

Figure 6. Total polar VOC loading in the ISS cabin. 


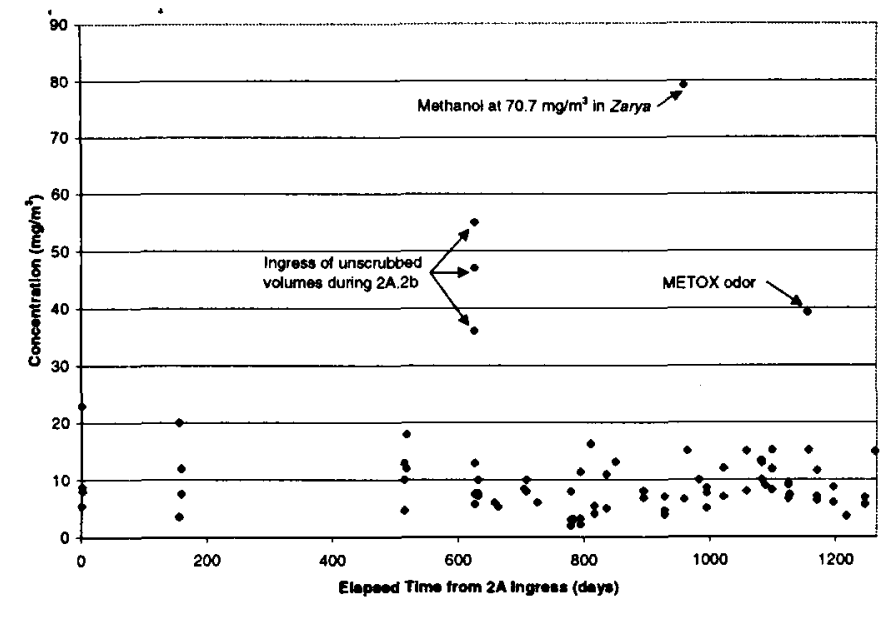

Figure 7. Non-methane VOCs Excluding Freon 218

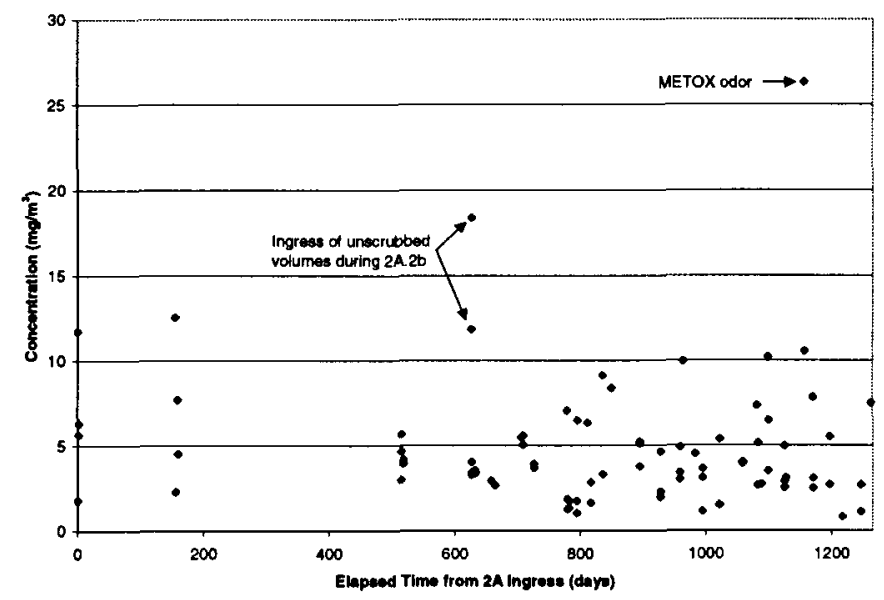

Figure 8. Non-methane VOCs Excluding Freon 218 and Alcohols

\section{SPATIAL DYNAMICS}

The elevated methanol concentration in Zarya demonstrates that local transients are possible. Even so, the entire ISS cabin usually remains nearly well mixed with some noted exceptions. Figure 9 shows the total polar VOC distribution by module beginning with Zvezda's activation during mission $2 R$ in October 2000. As can be seen, the measured concentrations in Zvezda and Destiny follow each other closely indicating good ventilation exchange between them. An increasing trend is evident with significant peaks in Zvezda indicating local polar VOC use. As well, there are instances where the loading in Zarya is noticeably higher. The overall upward trend in concentration coincides with a period of time that the TCCS was not operating. After the TCCS returned to operation, the concentration decreased. Figure 10, that shows the non-methane VOC concentration excluding alcohols and Freon 218, also indicates good mixing between Zvezda and Destiny with typically higher concentrations in Zarya. . This is attributed to the inter-modular ventilation configuration that exists. Cabin air is forced from Zvezda forward to Node 1, Unity, and Destiny. This creates a local high pressure zone in the forward part of the station's cabin resulting in plenum flow back through
Zarya toward Zvezda. Therefore, Zarya depends on this passive inter-modular ventilation exchange for air quality control. Additionally, Zvezda and Destiny contain the station's active contamination control systems while Zarya has no active contamination control system normally operating. As a result, it is not surprising that higher concentrations in Zarya occur periodically. The concentrations in Zarya also exhibit an increasing trend indicative of either a local generation source or degrading ventilation.

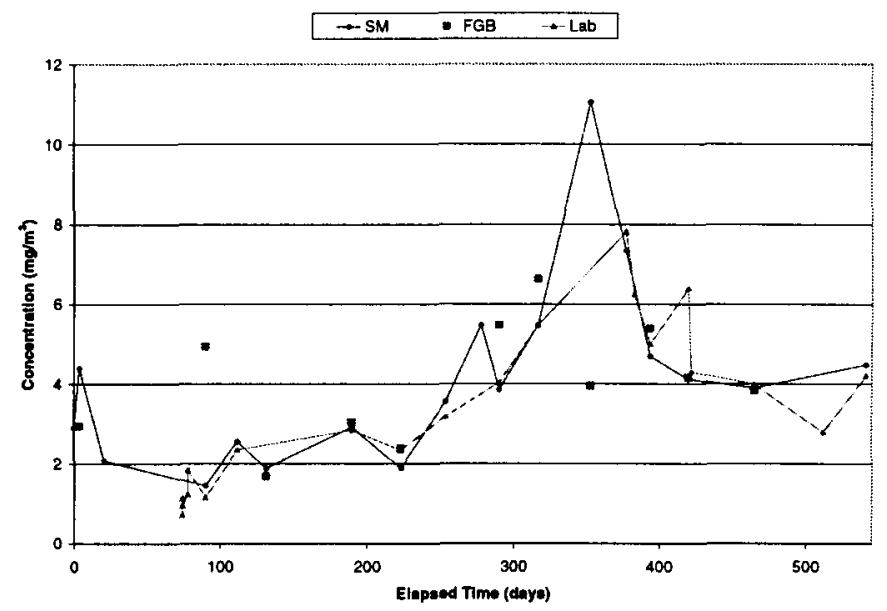

Figure 9. Spatial Distribution of polar VOCs Onboard the ISS

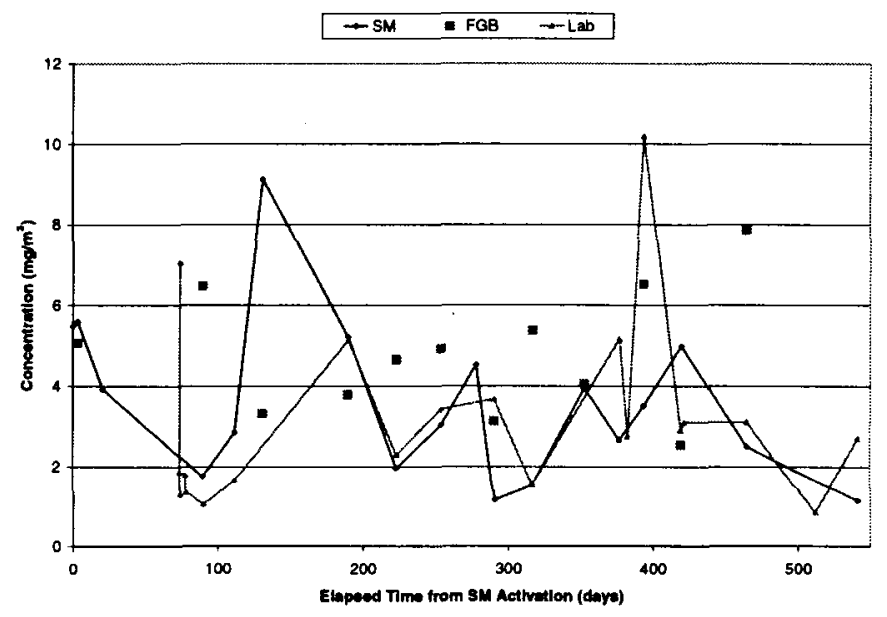

Figure 10. Spatial Distribution of Non-methane VOCs Excluding Freon 218 and Alcohols

\section{CARGO VEHICLE CABIN AIR QUALITY DYNAMICS}

The multi-purpose logistics module (MPLM) is used to transport equipment and supplies to and from the ISS. Therefore, the MPLM represents a potential source of trace chemical contaminants. As well, while berthed to the station the MPLM cabin air quality is influenced by the prevailing conditions in the ISS's cabin. The composition of the ISS's trace contaminant load is characterized in Figure 1. The MPLM, however, is filled with fresh breathing air before flight and its cabin air quality at crew entry in flight reflects the buildup of contaminants during 
the elapsed time between closeout on the ground and docking with the ISS. On average, the MPLM cabin air quality is characterized as shown by Figure 11. Alcohols, organosilicones, ketones, halocarbons, and aldehydes are the primary functional classes present. Ethanol, 2propanol, n-butanol, 2-propanone, dichloromethane, and polymethycyclosiloxanes are the most prevalent individual compounds. Methane also is a contributor but its presence in the samples collected upon crew entry reflects some atmospheric mixing between the MPLM and ISS volumes. Overall, the non-methane VOCs account for $88 \%$ of the total load.

During the docked phase, the MPLM and ISS volumes mix. The resulting trace contaminant composition reflects that shown by Figure 1. During this time, the crew unloads new supplies and equipment and then packs the MPLM with old equipment, trash, and other items for the return trip. Upon return to the ground, samples collected from the MPLM indicate cabin air quality with the average composition illustrated by Figure 12. While the percentage of the load provided by methane rises, the nonmethane VOCs still account for $72 \%$ of the total trace contaminant load. Interestingly, the percentage of the load contributed by the organosilicone compounds increases substantially. Alcohols are also major contributors as are ketones. Halocarbons and aldehydes are reduced substantially. Of the dominant contaminant classes, all but the organosilicones and methane appear to have been diluted by a less contaminated station atmosphere.

These overall observations on the composition of the MPLM's trace contaminant load identify specific classes to evaluate more closely with respect to their temporal dynamics. The following discussion provides additional details on methane, polar VOCs, halocarbons, and nonmethane VOCs. In addition, results from post-flight samples collected from the MPLM that show the presence of ethylene are discussed.

\section{SPATIAL AND TEMPORAL DYNAMICS}

The high ethanol concentrations reported during STS$106 / 2 A .2 b$ demonstrate the contamination potential of new modules and equipment as they are brought to the station. Therefore, passive contamination control techniques to limit polar VOC use during ground processing close to final vehicle closeout are key to minimizing inflight air quality impacts. The MPLM provides a vivid example of the need for continual attention to contamination control issues during logistics module ground processing. By restricting polar VOC use within the last 5 days before closing the MPLM"s hatch, the total load at crew entry has been reduced from nearly $10 \mathrm{mg} / \mathrm{m}^{3}$ to as low as $5 \mathrm{mg} / \mathrm{m}^{3}$. This nearly $50 \%$ reduction in the total polar VOC load on board the MPLM continued until STS$111 /$ UF-2 when analysis of the ingress sample reported nearly $7.5 \mathrm{mg} / \mathrm{m}^{3}$ of total polar VOCs. Ethanol, 2propanol, and 2-propanone-solvents used during MPLM ground processing-accounted for $85 \%$ of this concentration. This illustrates that continued vigilance is necessary when implementing passive contamination controls during vehicle launch processing operations.

The MPLM also experiences cabin air quality dynamics associated with its transportation to and from the ISS. It is sealed on the ground and not opened until the crew enters it on orbit. During this time, contamination accumulates. After the crew enters and establishes ventilation with the ISS, the MPLM's contamination levels decline as they dilute with the ISS's atmosphere. A second period of contamination accumulation occurs during the MPLM's transportation from orbit to the ground. The following discussion highlights observations on air quality dynamics associated with the MPLM's journey to the ISS and back.

\section{Methane, Halocarbons, and Light Alcohols}

A comparison of in-flight methane, halocarbon, and light alcohol concentrations within the MPLM to those in the ISS cabin show all components are below their respective SMAC with close correlation to concentrations reported in the MPLM samples collected post flight before

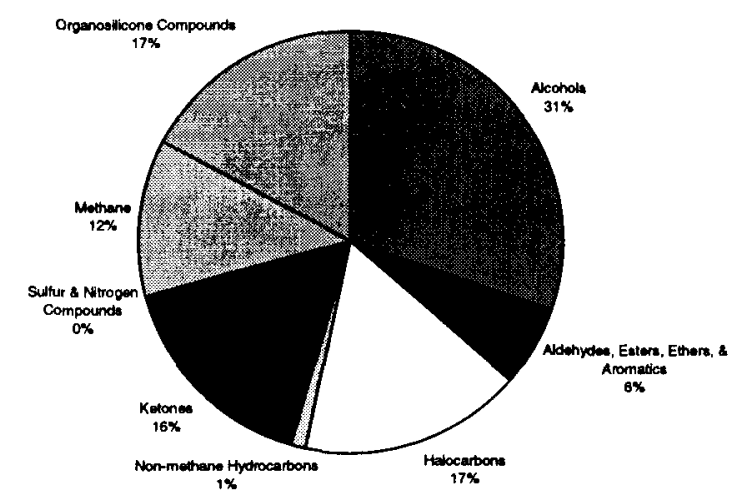

Figure 11. Average MPLM Trace Contaminant Load Composition upon Crew Entry

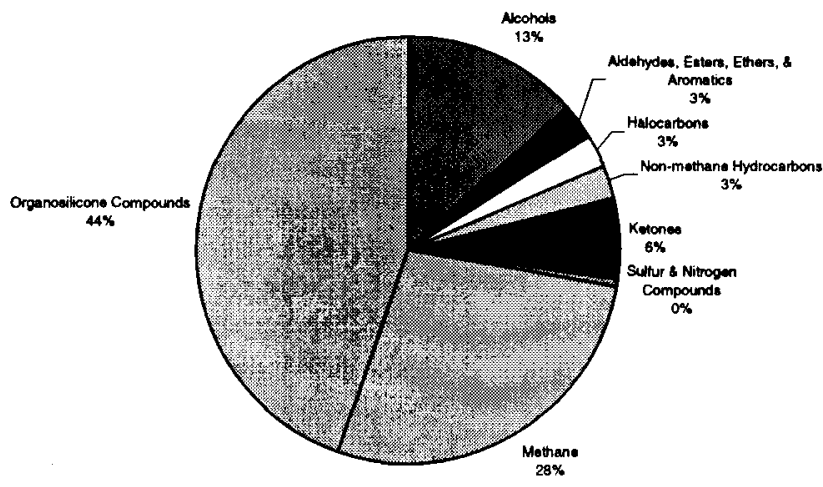

Figure 12. Average MPLM Post-flight Trace Contaminant Load Composition 
opening the hatch in the Space Station Processing Facility (SSPF), at the NASA's Kennedy Space Center (NASA KSC). Figure 13 shows the comparison of methane concentration. Typically, the methane concentration in the MPLM upon crew entry is much lower than that in the ISS cabin. However, post-flight sampling shows methane concentrations that are higher than those reported in samples collected from the ISS cabin. It is possible that microbial action in the some of the returning materials contributed to the higher loading. Also, the elapsed time between MPLM undocking and post-flight sampling in the SSPF may play a role. For instance, the post-flight MPLM sample for the $14^{\text {th }}$ ISS mission, UF-2, shows an exceedingly higher trace contaminant loading than that reported from samples collected from the ISS during the same time. The elapsed time between MPLM undocking from the ISS and sampling on the ground was much longer for this flight due to the shuttle's landing at Edwards Air Force Base (EAFB), California, followed by a ferry flight to NASA KSC. Undocking from the ISS was June 15,2002 . Landing was 4 days later and the sample was not collected until July 15, 2002, 30 days after undocking. All other flights landed at NASA KSC. Postflight sampling took place 10 days, 17 days, 10 days, and 24 days after undocking from the ISS for missions 5A.1, $6 A, 7 A .1$, and UF-1, respectively.

Figure 14 summarizes the halocarbon loading of the MPLM at crew entry during flight and post flight compared to the ISS cabin. As can be seen, the halocarbon loading in the MPLM at the time of crew entry is much greater than that in the ISS cabin. This indicates that the equipment being brought to the ISS is a significant source of halocarbons. Dichloromethane is a major component of this halocarbon load as indicated by Figure 3. This summary does not include Freon 218. As discussed earlier, a Freon 218 leak resulted in a substantial increase of total the non-methane VOC concentration in the samples collected from the MPLM and ISS during missions 6A, 7A, and UF-1. While the Freon 218 concentration was far below its SMAC of $85,00 \mathrm{mg} / \mathrm{m}^{3}$, it spreads from the ISS into the MPLM once cabin ventilation is initiated for docked operations. Freon 218 was detected, but not quantified, in post-flight MPLM samples collected in the SSPF. Spectra with matching ion fragmentation were found in 5A.1, 7A.1 and UF-2, OFP may be present but is not confirmed due to co-eluting compounds with the analytical procedure. The total halocarbon load appears to decrease in the MPLM upon sampling in the SSPF with the exception of the UF-2 mission.

The light weigh alcohol and 2-propanone concentrations in the MPLM are typically elevated compared to the ISS cabin in samples collected at both crew entry and postflight as shown by Figure 15 . Ethanol and 2-propanol are the major contributors and 2-propanone contributed significantly to the load at crew entry during flight UF-2. This may be due to cleaning and processing of the supplies prior to launch of the MPLM as well as in-flight equipment cleaning just before the return flight.

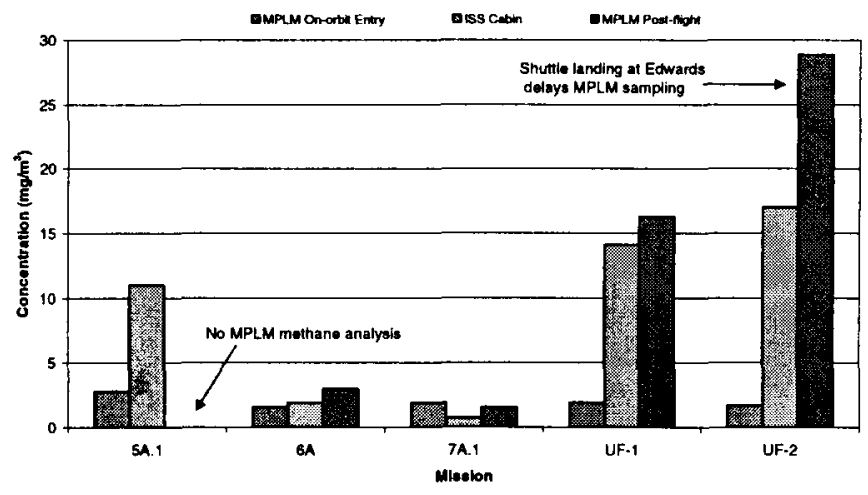

Figure 13. MPLM In-flight and Post-flight Methane Concentration Compared to ISS Cabin

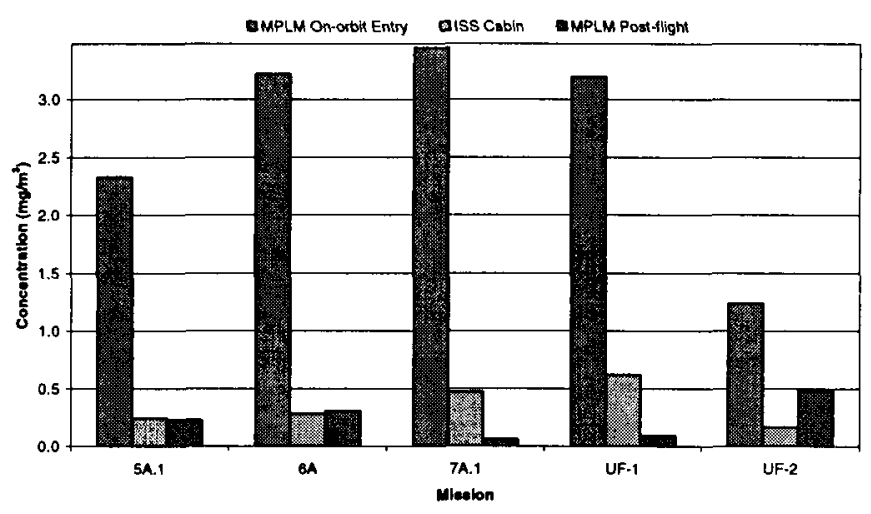

Figure 14. MPLM In-flight and Post-flight Halocarbon Concentration Compared to ISS Cabin

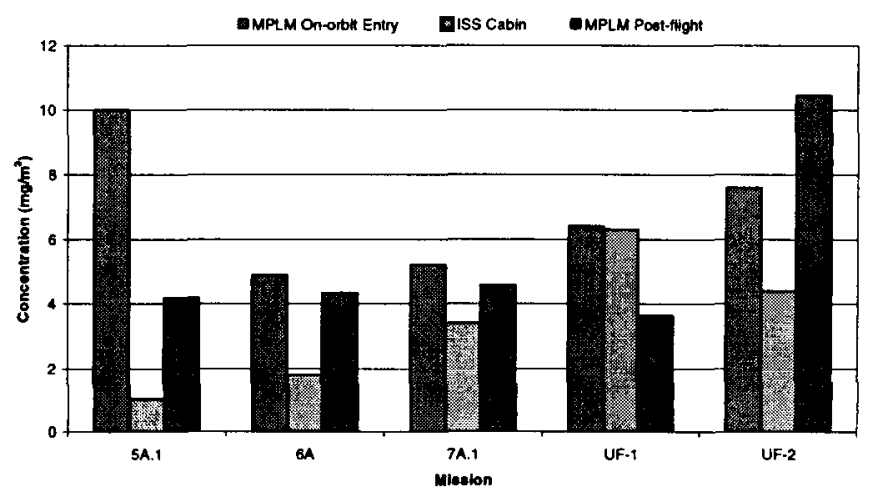

Figure 15. MPLM In-flight and Post-flight Polar VOC Concentration Compared to ISS Cabin

\section{Non-methane VOCs}

Figure 16 shows the MPLM's non-methane VOC concentration at crew entry and post flight compared to that of the ISS cabin. The basic trend-an elevated concentration at crew entry and post flight-is consistent with those observed for the halocarbons, light alcohols, and 2-propanone. Compared with Figure 15, it is evident that the polar VOCs contribute significantly to the total nonmethane VOC loading. Again, the increased elapsed time between landing at EAFB and post-flight sampling at the SSPF for flight UF-2 contributes to the significantly higher post-flight loading. Beyond the polar VOCs, the other major contributor in the 7A.1 post-flight sample is octamethylcyclotetrasiloxane, an offgassing 


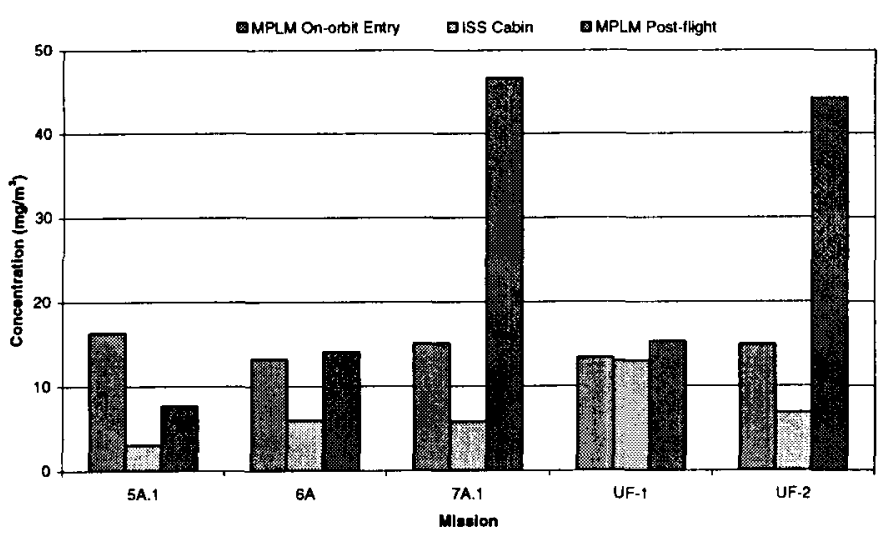

Figure 16. MPLM In-flight and Post-flight Non-methane VOC Concentration Compared to ISS Cabin

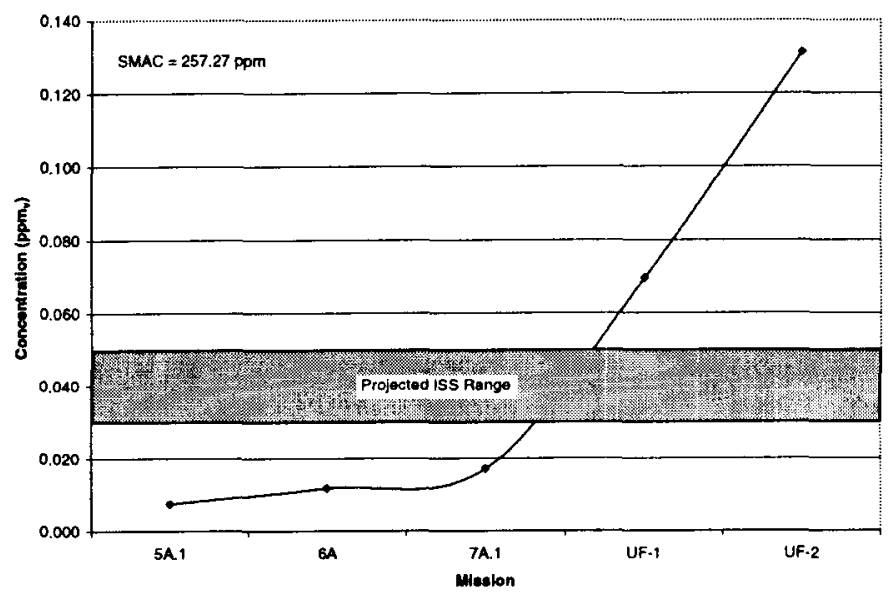

Figure 17. MPLM Post-flight Ethylene Concentration

product of sealants, adhesives, and silicone-based seals and grease. It also contributes significantly to the nonmethane VOC loading observed during UF-2.

\section{ETHYLENE}

Life Science experiments with plants in closed systems such as ISS are sensitive to ethylene. Ethylene is a volatile hormone produced by all higher plants. It coordinates and regulates the growth and development of plants with germination, leaf expansion, flower formation and senescence.[12] Excessive amounts of ethylene signal plant injury and eventually cause plant death. A build-up of ethylene in a closed plant growth chamber experiment may have been a factor in developmental changes in plant growth.[13]

Sources of ethylene in a spacecraft are both biogenic, from plant and microbial metabolism, and anthropogenic.[14] There is a potential for acute exposure because of a lack of convective currents in the immediate vicinity of the plants and a potential failure of ethylene removal systems.[15] In predicting ethylene concentrations for the ISS, it was anticipated that a range from 0.03-0.05 $\mathrm{ppm}_{\mathrm{y}}$ was possible.[16] This was taking into account both fresh food and decomposition of food and waste.
All ethylene concentrations measured from in-flight samples collected in both the ISS and MPLM were found to be less that $0.6 \mathrm{mg} / \mathrm{m}^{3}\left(0.5 \mathrm{ppm}_{\mathrm{v}}\right)$, the detection limit for this analysis. Figure 17 summarizes the ethylene concentrations observed in the 5 MPLM post-flight sample analyses. The detection limit for measuring ethylene at the NASA KSC laboratory is much lower than $0.6 \mathrm{mg} / \mathrm{m}^{3}$ to accommodate the demanding requirements of plant growth experiments.[17] As can be seen, a slowly increasing trend is noted for the period between 5A.1 and 7A.1. Flights UF-1 and UF-2, however, are much greater. Wet trash and offgassing of materials in the MPLM may account for the higher concentrations for flights UF-1 and UF-2. Further support is provided by the correlation with this trend and that for post-flight methane concentration illustrated by Figure 13. In addition, the longer elapsed elapsed time between undocking from the ISS and postflight sample collection in the SSPF may account for the even higher concentration found in the UF 2 sample.

\section{SUMMARY}

Evaluation of both in-flight and post-flight cabin air quality samples from the ISS demonstrates that even though the on-board contamination control systems and passive controls implemented to minimize contamination sources is maintaining acceptable cabin air quality, significant spatial and temporal effects can occur. Such effects are directly influenced by the station's configuration, the operation of on-board contamination control equipment, equipment failures. Chief contributors to the total trace contaminant load include methane, alcohols, and organosilicones. Minor contributors include ketones, halocarbons, hydrogen, and carbon monoxide.

The air quality within the MPLM is influenced by ground processing operations and the elapsed time that it is sealed during its transportation to the ISS and subsequent return to the ground. The composition of the MPLM's trace contaminant load has similarities to that in the ISS cabin. However, organosilicone compounds, alcohols, and methane show increases in concentration post flight. The equipment and other cargo contained in the MPLM during its return to the ground may contribute to the production of ethylene, a compound of concern to investigators of plant growth payloads. It is also possible that ethylene is present on board the ISS but below standard analytical method detection limits.

\section{CONCLUSIONS}

While the ISS cabin air quality is influenced by a variety of factors, the passive and active controls in place have been effective in controlling the overall trace contaminant loading. Efforts to minimize the introduction of polar VOCs into the ISS cabin with each MPLM flight have achieved some improvement but continued vigilance is required. Ethylene has been observed in samples collected from the MPLM post-flight. While ethylene has not been detected in samples collected during flight, it is possible that it is present but below the analytical method 
detection timit. Efforts to understand the magnitude of ethylene's concentration on board the ISS would be beneficial to researchers involved with experimental plant growth payloads.

\section{ACKNOWLEDGMENTS}

The authors express their gratitude to the personnel that analyze the cabin air samples that serve as the basis for the assessment of air quality dynamics on board the ISS. They are Dynamac Corporation, NASA Kennedy Space Center, Florida, the NASA Johnson Space Center Toxicology Group, and Wyle Laboratories, Houston, Texas.

\section{REFERENCES}

1. Limero, T.F.; Taylor, R.D.; Pieson, D.L.; and James, J.T.: Space Station Freedom Viewed as a "Tight Building". SAE 901382. 20 $0^{\text {th }}$ International Conference on Environmental Systems. Society of Automotive Engineers: Warrendale, PA; July 1990.

2. Perry, J.L.: Elements of Spacecraft Cabin Air Quality Control Design. NASATP-1998-207978. NASA Marshall Space Flight Center: MSFC, AL; May 1998, pp. 1-5.

3. Perry, J.L.; Curtis, R.E.; Alexandre, K.L.; Ruggiero, L.L.; and Shtessel, N.: Performance Testing of a Trace Contaminant Control Subassembly for the International Space Station. SAE 981621. $28^{\text {th }}$ International Conference on Environmental Systems. Society of Automotive Engineers: Warrendale, PA; July 1998.

4. Curtis, R.E.; Perry, J.L.; and Abramov, L.H.: Performance Testing of a Russian Mir Space Station Trace Contaminant Control Assembly. $27^{\text {th }}$ International Conference on Environmental Systems. Society of Automotive Engineers: Warrendale, PA; July 1997.

5. Perry, J.L.: Elements of Spacecraft Cabin Air Quality Control Design. NASATP-1998-207978. NASA Marshall Space Flight Center: MSFC, AL; May 1998, pp. 43-47.

6. Wieland, P.O.: Living Together in Space-The Design and Operation of the Life Support Systems on the International Space Station. NASATM-1998206956. NASA Marshall Space Flight Center: MSFC; Alabama; January 1998.

7. Perry, J.L.; James, J.T.; Cole, H.E.; Limero, T.F.; and Beck, S.W.: Rationale and Methods for Archival Sampling and Analysis of Atmospheric Trace Chemical Contaminants On Board Mir and Recommendations for the International Space Station. NASA TM-108534. NASA Marshall Space Flight Center: MSFC, Alabama; April 1997.

8. Spacecraft Maximum Allowable Concentrations for Selected Airborne Contaminants, Volume 1 National Academy Press, Washington D.C. 1994.
9. Spacecraft Maximum Allowable Concentrations for Selected Airborne Contaminants, Volume 2 National Academy Press, Washington D.C. 1996.

10. Spacecraft Maximum Allowable Concentrations for Selected Airborne Contaminants, Volume 4 National Academy Press, Washington D.C. 1996

11. Perry, J.L.: The Interaction of Spacecraft Cabin Atmospheric Quality and Water Processing System Performance. SAE 2002-01-2300. $32^{\text {nd }}$ International Conference on Environmental Systems. Society of Automotive Engineers: Warrendale, PA; July 2002.

12. Abeles, F. B.; Morgan, P.W.; and Saltveit, M.S.: Ethylene in Plant Biology, $2^{\text {nd }}$ Edition. Academic Press: New York; 1992.

13. Stutte, G. W. and Peterson, B.V: Biogenic Organic Compound Production by Soybean and Tomato. Pro. Plant Growth Regul. Soc. Amer. Calgary, Alberta, Canada 23: 295-300. 1996.

14. Stutte, G. W. and Wheeler, R.M.: Accumulation and Effect of Volatile Organic Compounds in Closed Life Support Systems. Adv. Space Res. Vol. 20, No. 10, pp. 1913-1922. 1997.

15. Wheeler, R. M.; Peterson, B.V.; Sager, J.C.; and Knott, W.M.: Ethylene Production by Plants in Closed Environment. Adv. Space Res. 18:193-196. 1996.

16. Reuter, J.: International Space Station Internal Environments. Presentation to Space Station Utilization Advisory Subcommittee Summer Workshop. June 1999.

17. Peterson, Barbara V.: Internal Operating Procedures. Dynamac Corporation, Organic Analytical Chemistry Laboratory: Kennedy Space Center, FL.; 2000.

\section{CONTACT}

Jay L. Perry

National Aeronautics and Space Administration

Marshall Space Flight Center

FD21

Marshall Space Flight Center, AL 35812

Phone: 256-544-2730

Fax: 256-544-0920

Jay.L.Perry@nasa.gov

Barbara V. Peterson

Dynamac Corp.

DYN-2

Kennedy Space Center, FL 32899

Phone: 321-476-4118

Fax: 321-853-3281

peterbv@kscesm.ksc.nasa.gov 